\title{
O LETRAMENTO DO EDUCANDO SURDO EM LÍNGUA PORTUGUESA
}

\author{
THE LITERACY OF DEAF LEARNERS IN PORTUGUESE
}

EL LETRAMENTO DE SORDOS EN LENGUA PORTUGUESA

Lígia de Souza Araújo Santana*

\section{Resumo}

Este artigo retoma alguns aspectos dos direitos que garantem educação para todos, com atenção voltada a questões relacionadas à educação dos surdos e apresenta, de forma sucinta, alguns dos pressupostos das principais abordagens associadas a correntes linguísticas que fundamentam os métodos do ensino de línguas, como as de Vygotsky e Bakhtin. O objetivo desta pesquisa é trazer reflexões sobre a ação de professores de Língua Portuguesa, tanto na identificação das potencialidades dos alunos, como na percepção das características do educando surdo, especialmente no que diz respeito à aquisição da Língua Portuguesa como segunda língua e à utilização dos gêneros textuais no letramento do aprendiz surdo em uma perspectiva bilíngue.

Palavras-chave: Língua Brasileira de Sinais. Interacionismo. Gêneros Textuais.

\section{Introdução}

Pesquisas envolvendo estudos sobre a Educação Inclusiva são recorrentes em cursos de Graduação e Pós-Graduação, lato sensu e stricto sensu, em Educação e áreas afins. Os pesquisadores se debruçam sobre esse tema de acordo com diferentes perspectivas, na certeza de que muitas respostas ainda estão a caminho. Políticas públicas mencionam a Declaração de Salamanca (1994) e os seus objetivos de garantir a educação para todos. Quadros (2005) afirma que "surdos, cegos, deficientes físicos, negros, índios, brancos, pobres deveriam ter acesso à escola. Isso significa situar a educação especial dentro de uma perspectiva muito mais abrangente", considerando ainda que, ao se propor uma educação inclusiva,

\footnotetext{
* Mestranda no PPGEEB do CEPAE, Universidade Estadual de Goiás - UFG, Graduação em Letras na UFG. Professora da rede estadual de educação- SEDUCE, onde atua na área do ensino especial. Professora de libras na Faculdade Araguaia. E-mail: ligsas@hotmail.com.
} 
[...] supõem-se a existência de excluídos. Assim, a reflexão deve ser feita tendo em vista esta oposição que sustenta a política educacional nacional. Dessa forma, a educação deveria estar calcada em um plano que atenda de fato as diferenças no contexto brasileiro: diferenças sociais, políticas, linguísticas e culturais (QUADROS, 2005, p.123).

Quadros (2005) observa que a Declaração de Salamanca considerou como uma peculiaridade da educação de surdos a língua imersa em cultura surda. Para Quadros, embora as questões linguísticas sejam essenciais, não são exclusivas, quando o que se propõe é uma educação que atenda às especificidades do aluno surdo. A autora apresenta outras questões, relacionadas à formação de identidade, tipos de interações sociais, representações e papéis desempenhados pelos surdos dentro da sociedade. Essas questões estão presentes em sua formação escolar e na própria discussão sobre as línguas.

Para Geraldi (2015) a linguagem é uma forma de encontro, desencontro e confronto de posições. É através dela que nossas posições se tornam públicas. Geraldi (2015, p.34) afirma que a linguagem é a "condição sine qua non na apreensão e formação de conceitos que permitem aos sujeitos compreender o mundo e nele agir”. A partir dessas considerações, priorizamos neste artigo a questão linguística do educando com surdez.

\section{Abordagens linguísticas}

Acreditamos que adotar uma abordagem implica estabelecer uma concepção de língua que servirá de base para definir como esta deverá ser ensinada e aprendida. É posicionar-se. De acordo com Salles et al (2004) são três as abordagens associadas a correntes linguísticas que fundamentaram os métodos desenvolvidos neste século: o estruturalismo, o funcionalismo e o interacionismo. Apresentaremos de forma sucinta os principais pressupostos dessas abordagens para o ensino de línguas.

\subsection{Estruturalismo}

$\mathrm{Na}$ abordagem estruturalista dos anos 50 e 60, a língua é concebida como um sistema de elementos relacionados estruturalmente, usados para a codificação e decodificação do significado. Aprender uma língua é cumprir o objetivo de dominar estes elementos. Os pressupostos teóricos do estruturalismo enfatizam as estruturas da língua e também as ideias da psicologia behaviorista que defende o condicionamento, o reforço positivo e a formação de 
hábitos como base para a aprendizagem. Assim sendo, a prática pedagógica estruturalista apoia-se na memorização de estruturas por meio de repetições e exercícios mecânicos.

Ferdinand de Saussure foi o precursor do estruturalismo e suas ideias tornaram-se conhecidas com a publicação póstuma, em 1916, da obra Curso de Linguística Geral, organizada por dois de seus alunos a partir de anotações das aulas do mestre. Nessa obra, Saussure apresenta suas conhecidas dicotomias e elege a língua em oposição à linguagem como objeto central da Linguística.

Antes de apresentar o funcionalismo, faz-se necessário mencionar o gerativismo postulado por Noam Chomsky, também na década de 50, que rejeita o behaviorismo e entende a capacidade humana de falar e compreender como uma capacidade genética. Tais argumentos levaram os estudiosos a repensarem o estruturalismo.

\subsection{Funcionalismo}

Na década de 70, o inglês Hymes, partindo da noção chomskyana do funcionamento da linguagem humana, ampliou o conceito de competência, denominando-o "competência comunicativa" e rompendo com o estruturalismo. De acordo com a concepção de linguagem funcionalista, a língua é concebida como um meio para a expressão de significados funcionais. Aprender uma língua implica não somente dominar as estruturas e itens lexicais, mas também aprender as regras pragmáticas e sociais da língua. Ou seja, um aprendizado que envolve dimensões semânticas e comunicativas.

$\mathrm{Na}$ ótica funcionalista o ensino de línguas vai além da estrutura linguística. Os exercícios mecânicos, repetitivos, podem ser usados, mas de forma periférica. O professor ajuda o aluno a trabalhar com a língua, considerando a exigência de contextualização e inclusão de variações linguísticas. Os erros passam a ser tratados como fenômenos que fazem parte da construção gradativa de aproximação do sistema da língua alvo.

Conforme Salles et al (2004) o ensino de segunda língua deixa de ser um processo de explicitação e domínio rígido de estruturas, passando a se apresentar como um processo dinâmico, no qual o aluno é visto como um usuário da língua, capaz de se comunicar em diferentes situações e contextos. Sob essa perspectiva, o professor precisará considerar as variações geográficas, sociais e de registros (formal e informal), além das diferenças entre as modalidades: oral e escrita. 


\subsection{Interacionismo}

Da década de 80 até os dias atuais, o Interacionismo enfatiza alguns apontamentos feitos pelos funcionalistas no tocante à comunicação. De acordo com a abordagem interacionista, segundo Richards e Rodgers (1986), citados por Salles et al (2004), a língua é concebida como um meio para a realização de relações interpessoais e para o desempenho de transações sociais entre indivíduos, sendo percebida com um instrumento para a criação e manutenção das relações sociais. A aprendizagem acontece no exercício comunicativo da interação, na construção do discurso. Mais do que considerar as funções comunicativas da língua, a perspectiva interacionista postula que o aluno vivencie a interação em sala de aula, transformando o ambiente em realidade discursiva.

Duas linhas teóricas fundamentam a abordagem interacionista: a Hipótese da Interação e a Teoria Sociocultural. O conceito principal da Hipótese da Interação é a negociação de significado que ocorre quando surgem problemas de compreensão no diálogo, levando o aprendiz a reformular sua produção. De acordo com essa linha teórica, a oportunidade de negociar o significado faz com que o aprendiz se atente à forma, enquanto processa a mensagem.

Baseada na proposta de Vygotsky, a Teoria Sociocultural defende que o desenvolvimento cognitivo acontece por meio da interação em situações sociais concretas e o aprendizado ocorre quando as funções mentais, determinadas biologicamente, evoluem para funções mais complexas de nível superior. Inicialmente essas funções são realizadas com a colaboração de outros e com a mediação do professor. Depois, passam a ser realizadas de forma independente. A língua é vista, portanto, como um instrumento mediador da construção do conhecimento (ELLIS, 1999 apud SALLES, et al, 2004).

\section{As contribuições do Interacionismo}

Conforme Salles et al (2004), cuja obra nos serviu de suporte para sintetizar as distintas abordagens, o Interacionimo apresenta uma série de vantagens para ensino da Língua Portuguesa para surdos. Os autores afirmam que a "abordagem interacionista configura-se como mais adequada, pois propõe o trabalho com a língua em uso, enfatizando interações contextualizadas voltadas para o desenvolvimento da competência comunicativa do aprendiz." (SALLES et al, 2004, p.82). 
Geraldi, estudioso de Bakhtin, discute em sua obra Linguagem e Ensino (1999) a construção de novas formas de ensinar e de aprender a Língua portuguesa. Na concepção de Geraldi (1999), a linguagem é compreendida como uma atividade constitutiva, cuja realização é a interação verbal, conforme salienta Bakhtin, dando-se pela internalização da palavra alheia (o falar do outro) e também a internalização de uma compreensão de mundo. Nessa orientação bakhtiniana sobre o dialogismo da linguagem, as palavras alheias vão perdendo suas origens, tornando-se, de forma ininterrupta, palavras próprias. Isso confirma que a língua não é um sistema fechado, pronto e acabado, do qual poderíamos nos apropriar, mas é, sim, dialógica.

Geraldi (1999) afirma que na concepção sociointeracionista da linguagem, o fenômeno social da interação verbal é o espaço próprio da realidade da língua. É a atividade social e interacional por meio da qual a língua, colocada em funcionamento é constitutiva tanto da própria linguagem e das línguas particulares, quanto dos sujeitos, cujas consciências sígnicas se formam nas interações de que os sujeitos participam e são por eles internalizadas. Bakhtin traçou as diretrizes da linguística interacionista.

Para Cunha (2005, p. 292), "Bakhtin foi o autor que melhor percebeu a importância do estudo da palavra de outrem e propôs a abordagem mais produtiva do fenômeno. Descreve o fenômeno de transmissão da fala na interação face a face". Segundo Brait (2012, p.27) o livro de Bakhtin Marxismo e Filosofia da linguagem "apresenta uma série de noções sem as quais seria impossível compreender a amplitude e o alcance da interação".

Um método eficaz e correto de ensino prático exige que a forma seja assimilada não no sistema abstrato da língua, isto é, como uma forma sempre idêntica a si mesma, mas na estrutura concreta da enunciação, como um signo flexível e variável (BAKHTIN; VOLOCHINOV, 1990, p.94-95. Nota de rodapé).

Do ponto de vista sociointeracionista da linguagem, a criança constitui-se como o sujeito que, ao construir para si uma linguagem que não é sua, mas de seu grupo social, advinda das interações de que fez parte, seu trabalho foi também constitutivo dessa linguagem: negociou sentidos, incorporou a seus conhecimentos prévios novos sentidos e constituiu-se como interlocutor, escolhendo estratégias de interação. Segundo Geraldi (2015), a criança, ao participar desse processo, compreende as falas dos outros, não aprende antes a linguagem para depois interagir. 
Ao discutir as mediações pedagógicas nos processos de produção de textos, Geraldi (2015) expõe o pensamento vygotskyano, base da Teoria Sociocultural e afirma que o desenvolvimento cognitivo não pode ser ensinado diretamente, enquanto o desenvolvimento psíquico representa, na verdade,

[...] uma função autônoma do aprendiz, mas esta função precisa do contexto social, das formas sociais de ensino-aprendizagem, ou seja, dos processos de mediação. [...] Vigotski introduz o famoso conceito de "zona de desenvolvimento proximal" que muda radicalmente a teoria sobre ensino/aprendizagem desenvolvimento. Vigotski denomina a capacidade de realizar tarefas de forma independente como o nível de desenvolvimento real. O nível de desenvolvimento potencial representa a capacidade de desempenhar tarefas com ajuda de adultos ou de companheiros mais capazes. A distância entre o nível de desenvolvimento real e o nível de desenvolvimento potencial Vigotski o define como "a zona de desenvolvimento proximal” (GERALDI, 2015, p.170. Grifos do autor).

Compreender o conceito de desenvolvimento potencial de Vygotsky e saber identificar as potencialidades do aprendiz permite-nos, segundo Geraldi (2015), antever os futuros passos do estudante e sua dinâmica de desenvolvimento.

\section{A questão do letramento}

Quadros (2005) afirma, com base na Declaração de Salamanca, de 1994, documento de referência mundial que orienta a educação inclusiva, que os alunos surdos devem ter direito de acesso ao conhecimento através da sua própria língua, a Língua Brasileira de Sinais, a Libras, e isso "significa muito mais do que dizer que ao aluno é permitido utilizar a língua de sinais, ou seja, a língua é o início,o meio e o fim das interações sociais, políticas e científicas" (Quadros, 2005, p.130). A autora elenca algumas implicações do reconhecimento do direito linguístico dos surdos:

1a aquisição da linguagem;

2a língua enquanto meio e fim da interação social, cultural, politica e cientifica;

3a língua como parte da constituição do sujeito, a significação de si e o reconhecimento da própria imagem diante das relações sociais (no sentido de Vygotsky, 1978);

4a língua enquanto instrumento formal de ensino da língua nativa (ou seja, alfabetização, disciplinas de língua de sinais como parte do currículo da formação de pessoas surdas); 
$5^{\mathrm{a}}$ língua portuguesa como uma segunda língua (alfabetização e letramento) (QUADROS, 2005, p.130)

O último item elencado pela autora nas implicações do reconhecimento do direito linguístico dos surdos é o destaque desse tópico, bem como de todo o artigo. Quadros diz que a aquisição da linguagem em crianças surdas deve acontecer por meio da Libras e isso independe de propostas pedagógicas, pois é algo pressuposto. De acordo com a autora, se a criança surda vai para a escola sem uma língua adquirida, a escola precisa atentar aos programas que garantam o acesso à Libras, mediante a interação social e cultural com pessoas surdas.

Quadros (2005) enfatiza a necessidade de organizar o currículo partindo de uma perspectiva visuoespacial, para garantir o acesso a todos os conteúdos escolares. Outra medida é a aceitação da Libras como língua usada pela escola desde o princípio. Segundo Quadros, ao se refletir "sobre a língua que a criança surda usa, a Língua de Sinais Brasileira, e o contexto escolar, também se pensa em letramento" (2005, p. 133). O conceito "letramento", que utilizamos neste trabalho, é o exposto por Magda Soares (2011, p.96):

Letramento é palavra e conceito recentes, introduzidos na linguagem da educação e das ciências linguísticas há pouco mais de duas décadas. Seu surgimento pode ser interpretado como decorrência da necessidade de configurar e nomear comportamentos e práticas sociais na área da leitura e da escrita que ultrapassem o domínio do sistema alfabético e ortográfico, nível de aprendizagem da língua escrita perseguido, tradicionalmente, pelo processo de alfabetização.

Os estudos do letramento, segundo Kleiman (2007), têm como objeto os aspectos e os impactos sociais da língua escrita. A escrita ganha destaque e, na análise de Marcuschi sobre o meio social contemporâneo, o autor é incisivo em afirmar que se trata de "um mundo decididamente grafocêntrico, em que o letramento é um fato onipresente com uma enorme crença na escrita e no seu poder e até mesmo no seu papel manipulador" (In KARWOSKI, 2011, p.27). Sob outra perspectiva, Geraldi (1999) afirma que a oralidade é característica de nossa cultura, alinhavando a importância tanto da oralidade como da escrita, para o letramento.

Vivemos numa sociedade letrada e para nos movimentarmos de um lugar para o outro acabamos necessitando de indicações registradas por escrito 
[...]. Aprender a ler é, assim, ampliar as possibilidades de interlocução com pessoas que jamais encontraremos frente a frente e, por interagirmos com elas, sermos capazes de compreender o mundo, as coisas, as gentes e suas relações. Isto é ler. E escrever é ser capaz de colocar-se na posição daquele que registra suas compreensões para ser lido por outros e, portanto, com eles interagir (GERALDI, 1999, p.70-71).

De acordo com Lodi (2015), a percepção de "ser letrado" não pode ser reduzida à aprendizagem da escrita como representação da oralidade. Para essa autora, ser letrado é participar ativamente de práticas discursivas letradas, sejam elas orais ou escritas, a partir dos variados materiais de circulação social propiciados pelas agências de letramento. Lodi observa que uma "obrigatoriedade da presença da escrita da língua majoritária vem sendo discutida quando no letramento de grupos ou comunidades socioculturais minoritárias (como por exemplo, a indígena e/ou outras culturas ágrafas), mas aparecem em segundo plano nos Estudos Surdos” (2015, p.14). No entanto, a questão da escrita nas línguas de sinais não está esquecida.

A escrita da língua de sinais surgiu com a criação da SignWriting pela americana Valerie Sutton, em 1974. É compreensível que os surdos queiram representar por meio da grafia suas expressões linguísticas, ao considerarem que a invenção da escrita revolucionou a humanidade. Acreditamos que o uso da escrita das línguas de sinais traria resultados semelhantes para a comunidade surda. A SignWriting ainda não foi totalmente difundida por parte dos linguistas, pesquisadores e governantes, mas tem sido aperfeiçoada e conseguido manifestações favoráveis, embora timidamente, segundo Quadros (2005).

Além da SignWriting, há o sistema de notação da Língua de Sinais Americana, de William Stokoe, que influenciou fortemente a criação da ELiS, um sistema brasileiro de escrita das línguas de sinais, criado pela professora goiana Mariângela Estelita Barros, que define a escrita ELiS como

[...] um sistema de escrita alfabético e linear, cujos caracteres, denominados visografemas [...] representam os elementos visuais que compõem as línguas de sinais, a saber, as configurações de dedos, orientações da palma, pontos de articulação, movimentos e expressões não manuais. Esses elementos são organizados em uma estrutura própria, que segue a dinâmica natural de formação dos sinais, ou seja, sua natureza sequencial cumulativa, que resulta em simultaneidade (BARROS, 2015, p.15). 
A ELiS tem revolucionado a educação de surdos no Brasil, pois possibilita a escrita sem a mediação de outra língua. Conforme Quadros (2005, p.133), "as crianças surdas tem sido alfabetizadas através de um processo similar às crianças ouvintes que dispõem do português como língua materna". Diante desse fato, alguns problemas foram diagnosticados.

Um dos problemas que deve ser reconhecido é que a escrita alfabética da língua portuguesa no Brasil não serve para representar significação com conceitos elaborados na língua de sinais brasileira, [...]. Um grafema, uma sílaba, uma palavra escrita no português não apresentam nenhuma analogia com um fonema, uma sílaba e uma palavra na língua de sinais brasileira, mas sim com o português falado (QUADROS, 2005, p.133).

De acordo com Quadros (2005), a ideia de a língua falada passar a ter uma representação secundária, retoma uma das diferenças essenciais do ser surdo. Salles et al (2004) e Quadros (2005) pressupõem que a língua de sinais deva ser considerada e desenvolvida como primeira língua dos surdos, e propõem a língua portuguesa escrita como segunda língua. As práticas educacionais para o ensino de segunda língua precisam ser conhecidas, estudadas e aplicadas pelos educadores para o ensino do Português escrito, afirma Quadros (2005). Não se pode ensinar a língua portuguesa como algo estático ou simplesmente como o domínio das regras gramaticais. De acordo com Lodi,

Centrar o ensino apenas no aspecto gramático não basta para a formação de sujeitos letrados, pois o acesso à escrita só será pleno quando ela for tratada e concebida como prática social de linguagem, cultural, social, histórica e ideologicamente determinada (2015, p.23).

Em uma sociedade altamente letrada, não é possível deixar de lado, nos processos de letramento, os gêneros da escrita. Atentando para o fato de que "a teoria dos gêneros não serve tanto para a identificação de um gênero como tal e sim para a percepção de como o funcionamento da língua é dinâmico e, embora sempre manifesto em textos, nunca deixa de se renovar nesse processo" (MARCUSCHI, In KARWOSKI, 2011, p. 18). Esse autor, refletindo com mais propriedade esta questão, afirma:

[...] o estudo dos gêneros textuais é uma fértil área interdisciplinar, com atenção especial para o funcionamento da língua e para as atividades culturais e sociais. Desde que não concebamos os gêneros como modelos estanques nem como estruturas rígidas, mas como formas culturais e 
cognitivas de ação social corporificadas de modo particular na linguagem, veremos os gêneros como entidades dinâmicas (MARCUSCHI, In KARWOSKI, 2011, p.18. Grifos do autor).

Compreendemos gêneros textuais a partir da definição de Marcuschi (2007, p. 29), quando afirma que "não há como fazer uma lista fechada de todos os gêneros". Sobre a expressão "gênero textual", Marcuschi observa que essa é usada como:

[...] uma noção propositalmente vaga para referir os textos materializados que encontramos em nossa vida diária e que apresentam características sócio-comunicativas definidas por conteúdos, propriedades funcionais, estilo e composição característica. Se os tipos textuais são apenas meia dúzia, os gêneros são inúmeros. Alguns exemplos de gêneros textuais seriam: telefonema, sermão, carta comercial, carta pessoal, romance, bilhete, reportagem jornalística, aula expositiva, reunião de condomínio, notícia jornalística, horóscopo, receita culinária, bula de remédio, lista de compras, cardápio de restaurante, instruções de uso, outdoor, inquérito, policial, resenha, edital de concurso, piada, conversação espontânea, conferência, carta eletrônica, bate-papo por computador, aulas virtuais e assim por diante (MARCUSCHI, In, DIONÍSIO; MACHADO; BEZERRA, 2007, p.22- 23. Grifos do autor).

O estudo dos gêneros textuais tem contribuído de forma segura para o letramento do aluno surdo. De acordo com Marcuschi, "a população em geral, e em particular as comunidades de baixo nível de letramento, mais consomem do que produzem gêneros e, mesmo assim, gêneros minimalistas" (2011, p.30). Assim sendo, a interação intensa e contínua com diferentes gêneros textuais possibilitará ao aluno surdo sair da condição de consumidor para a condição de produtor de textos diversificados. Em suas reflexões sobre o ensino da língua, Marchuschi (2007) indaga se haveria gêneros ideais para essa atividade e, como resposta, afirma que tudo indica que não. No entanto, Marchuschi (In DIONÍSIO; MACHADO; BEZERRA, 2007, p.36) sugere ser "provável que se possam identificar gêneros com dificuldades progressivas, do nível menos formal ao mais formal, do mais privado ao mais público e assim por diante".

O trabalho com gêneros textuais é "proposta oficial dos Parâmetros Curriculares Nacionais que insistem nesta perspectiva" (MARCUSCHI In: DIONÍSIO; MACHADO; BEZERRA, 2007, p.36). Diversos pesquisadores se debruçam na problemática de como trabalhar com os diferentes gêneros textuais na aula de Língua Portuguesa. Souza (2013, p.259) observa "que os gêneros textuais ajudam significativamente na aquisição da segunda 
língua pelos alunos surdos na modalidade escrita, na interpretação e na leitura, pois permite ao aluno vivenciar o texto de acordo com a sua função social”.

Souza (2013) aponta pesquisas, como a de Salles (2004), cujos resultados comprovam a eficácia dos gêneros textuais para o letramento do educando surdo. São estudos que possibilitam depreender a importância da utilização dos gêneros textuais, que permitem ao aluno surdo vivenciar o texto de acordo com a sua função social, além de contribuir na aquisição da Língua Portuguesa como L2 na modalidade escrita.

\section{Considerações finais}

A observação de que o letramento do educando surdo se concretiza por meio de uma língua visuoespacial sugere a necessidade de uma renovação nas metodologias de ensino para surdos, um fato preconizado por pesquisadores da aquisição da Língua Brasileira de Sinais, como Karnopp (1994) e Quadros (2005), entre outros. Geraldi afirma: “O novo não está no que se diz, mas no ressurgimento do já dito que se renova" (2015, p.81). No entanto, é sabido que muitos obstáculos deverão ser vencidos. Quadros (2005) levanta uma série de questões, relacionadas ao aprendizado do aluno surdo. Como a escola poderá garantir o processo de aquisição da linguagem através da Língua Brasileira de Sinais? Quem serão os interlocutores dos alunos surdos na sala de aula regular? Como a escola garantirá o acesso aos conhecimentos escolares na língua de sinais, uma vez que utiliza o Português como língua oficial? A autora também traz questões sobre a alfabetização na escrita de língua de sinais e as garantias do acesso ao Português, com estratégias de ensino baseadas na aquisição de segunda língua.

Para que sejam alcançados os objetivos propostos pelas Políticas Públicas, confirmando a Declaração de Salamanca (1994), de garantir a educação para todos, Gadotti (1993, apud GERALDI, 1999, p.76-77) alerta ser “indispensável investir na formação do professor. Não há material didático tão perfeito que possa substituir a presença do organizador da atividade didática". Sobre a formação do professor, Geraldi (2015, p. 82) enfatiza a necessidade de, realmente, nos tornarmos professores:

[...] a relação com o conhecimento, mais do que a própria relação pedagógica, isto é, a relação com os aprendentes, desenhou os diferentes perfis profissionais cuja sequência constitui a história de nossa profissão [...] Nós nos formamos professores ao longo de alguns anos de estudos de certos 
conteúdos, que adquirimos, que encorpamos, e que nos remodelam, nos tornam a pessoa que não éramos. [...] O que pretendo discutir aqui é que talvez isto apenas nos forme, mas não nos torna professores.

Por outro lado, o autor afirma que não pretende atribuir ao professor um peso que ele não pode suportar solitariamente. Ao trazer para discussão as práticas de letramento na escola, Kleiman (1995, p.47, apud LODI, 2015, p. 24), afirma que os resultados deficientes não podem ser atribuídos somente aos professores, considerando que as falhas "são mais profundas, pois são decorrentes dos próprios pressupostos que subjazem ao modelo de letramento escolar".

Após a exposição dos estudos realizados sobre o tema o letramento do aluno surdo na sala de aula, na disciplina de Língua Portuguesa, é possível sinalizar a necessidade de práticas pedagógicas que atentem para a concepção de linguagem defendida pelos interacionistas, que valorize o trabalho com gêneros textuais diversificados, bem como o funcionamento dinâmico da língua, possibilitando assim ao educando fazer uso do que aprende em sala de aula para se comunicar nas diversas situações cotidianas.

Torna-se, portanto, imprescindível ao professor em turmas inclusivas assegurar ao educando surdo o ensino da língua portuguesa como segunda língua. Dessa forma, a língua de sinais e a língua portuguesa serão usadas tanto no contexto escolar quanto social. Acreditamos que, nessa perspectiva bilíngue, poderia ser ampliada, sobremaneira, a competência linguística e discursiva desse grupo específico, bem como a sua maior participação social.

\begin{abstract}
This article takes up some aspects of the rights that guarantee education for all, with attention focused on issues related to the education of the deaf and presents, briefly, some of the assumptions of the main approaches associated with linguistic currents that base the methods of language teaching, such as those of Vygotsky and Bakhtin. The purpose of this research is to bring reflections on the action of Portuguese Language teachers, both in identifying the potential of the students and in the perception of the characteristics of the deaf student, especially regarding the acquisition of Portuguese as a second language and the use of textual genres in the learner's literacy in a bilingual perspective.
\end{abstract}

Keywords: Brazilian Sign Language. Interactionism. Textual genres 


\section{Resumen}

Este artículo retoma algunos aspectos de los derechos que garantizan la educación para todos, poniendo atención en cuestiones relacionadas a la educación de los sordos y presenta, de forma sucinta, algunos de los supuestos de los principales enfoques asociados a corrientes lingüísticas que fundamentan los métodos de enseñanza de lenguas, como los de Vygotsky y Bakhtin. El objetivo de esta investigación es direccionar reflexiones sobre la acción de profesores de Lengua Portuguesa, tanto en la identificación las aptitudes de los estudiantes, como en la percepción de las características del estudiante sordo, especialmente en lo que se refiere a la adquisición de lengua, teniendo en cuenta la adquisición de Lengua Portuguesa como segunda lengua y el uso de los géneros textuales en el letramento del aprendiente sordo en una perspectiva bilingüe

Palabras clave: Lengua Brasileña de Señas. Interaccionismo. Géneros textuales.

\section{Referências}

BAKHTIN, M. M.; VOLOCHINOV, V. N.. Marxismo e Filosofia da Linguagem. São Paulo: Hucitec, 1990.

BRAIT, B. Análise e teoria do Discurso, in Brait, B. (Org.). Bakhtin: outros conceitoschave. São Paulo: Contexto, 2012.

BARROS, Mariângela Estelita. ELiS: sistema brasileiro de escrita das línguas de sinais. Porto Alegre: Penso, 2015.

CUNHA, D.A.C.. Bakhtin e a linguística atual: interlocuções, in BRAIT, B. (Org.).

Bakhtin: dialogismo e construção de sentidos. Campinas: Editora da Unicamp, 2005.

Declaração de Salamanca. Sobre Princípios, Políticas e Práticas na Área das Necessidades Educativas Especiais, 1994. Disponível em:

<http://portal.mec.gov.br/seesp/arquivos/pdf/salamanca.pdf> Acesso em: 03 nov. 2017.

GERALDI, João Wanderley. Linguagem e Ensino. Campinas: Mercado de Letras, 1999.

A aula como acontecimento. São Carlos: Pedro \& João Editores, 2015.

KARNOPP, L. B. Aquisição do parâmetro configuração de mão na Língua Brasileira de

Sinais (LIBRAS): estudo sobre quatro crianças surdas, filhas de pais surdos. Porto Alegre, PUC: Dissertação de Mestrado, 1994.

KARWOSKI, A. M. et al (Orgs). Gêneros textuais: reflexões e ensino. São Paulo: Parábola, 2011.

KLEIMAN, A. B.. Letramento e suas implicações para o Ensino de Língua Materna, In Signo. Santa Cruz do Sul, V.32 N.53 P.1-25, Dez 2007. 
LODI, Ana Claudia Balieiro, Letramento e Surdez: um olhar sobre as particularidades do contexto educacional, p.11-24, In: Letramento, bilinguismo e educação de surdos, LODI, A.; BALIEIRO C. et al (Orgs), Porto Alegre: Mediação, 2015.

MARCUSCHI, L. A. Gêneros textuais:configuração, dinamicidade e circulaçãa, In: KARWOSKI, A. M. et al (Orgs). Gêneros textuais: reflexões e ensino. São Paulo: Parábola, 2011.

Gêneros textuais, definição e funcionalidade. In: DIONÍSIO, A.; MACHADO, P. A. R.; BEZERRA, M. A. Gêneros textuais e Ensino. Rio de Janeiro: Lucerna, 2007, p.19-36.

QUADROS, Ronice Muller de. Inclusão de surdos, In: Ensaios pedagógicos: construindo escolas inclusivas. Brasília: MEC, SEESP, 2005. p.122-139.

RICHARD, C. J.; RODGERS, S. T.. Approaches and Methods in language teaching. Cambridge University Press, 1986.

SALLES, Heloísa Maria Moreira Lima et al. Ensino de Língua Portuguesa para surdos: caminhos para a prática pedagógica, v.1, Brasília: MEC, SEESP, 2004.

SOARES, Magda, Alfabetização e Letramento: caminhos e descaminhos, in Universidade Estadual Paulista. UNESP. Pró- Reitoria de Graduação. Caderno de Formação: Formação de professores. Didática dos Conteúdos. São Paulo: Cultura Acadêmica, 2011. V.2 193p (curso de Pedagogia), p.96-100. Disponível também em: Revista pátio-Revista Pedagógica de 29 de fevereiro de 2004. Ed. Artmed.

SOUZA, Iranilde dos Santos Rocha, Gêneros Textuais: uma proposta para o ensino de Língua Portuguesa para surdos, in Revista eletrônica da Faculdade José Augusto Vieira, Ano VI No 08 setembro 2013. Disponível em: http://www.fjav.com.br. Disponível também em: http: fjav. com.br/ revista/index.php.ISSN-1983-1285 